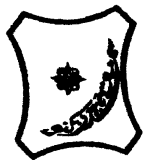

Bayero Journal of Pure and Applied Sciences, 8(2): 123 - 128

Received: September, 2015

Accepted: November, 2013

ISSN 2006 - 6996

\title{
AMELIORATIVE EFFECTS OF SELENIUM AND VITAMIN E SUPPLEMENTATION ON SOME HAEMATOLOGICAL PARAMETERS AND RED BLOOD CELL OSMOTIC FRAGILTY IN WISTAR RATS SUBJECTED TO WATER IMMERSION RESTRAINT STRESS
}

\author{
Sadau, Y. ${ }^{1 *}$ Adelaiye, A.B. ${ }^{2}$ Magaji, R.A. ${ }^{2}$ Ayo, J.O. $^{3}$ Isa, A.I. ${ }^{2}$ Mabruok, M.A. ${ }^{4}$ and Lai, I. ${ }^{1}$ \\ $1^{*}$ Department of Human Physiology, College of Medical Sciences, Gombe State University, Gombe, Nigeria. \\ 2 Department of Human Physiology, Ahmadu Bello University, Zaria, Nigeria \\ 3 Department of Veterinary Physiology and Pharmacology, Ahmadu Bello University, Zaria, Nigeria. \\ 4 Department of Human Physiology, College of Medical Sciences, Bayero University, Kano, Nigeria. \\ Corresponding author address Email: ysadau@gmail.com TEL: +2348065077877
}

\begin{abstract}
The aim of the present study was to determine the effects of selenium and vitamin $E$ supplementation on some haematological parameters and red blood cell osmotic fragility in Wistar rats subjected to water immersion restraint stress (WRS) $(n=35)$. Male Wistar rats, weighing $200-220 \mathrm{~g}$ were divided in to five groups of seven rats each, viz: (i) passive control (non-stress rats), (ii) active control (WRS + distilled water), (iii) WRS + vitamin E, (iv) WRS + vitamin E + selenium, and (V) WRS + selenium. The WRS procedure lasted for 3.5 hours. Blood samples were collected through cardiac puncture for the investigation of some haematological parameters and red blood cell osmotic fragility. The results of the present study showed that there were no significant changes (P>0.05) in PCV, $H b, R B C, W B C$, $M C V, M C H, M C H C$, Lymphocytes and monocytes and there was a significant decrease $(P>0.05)$ in neutrophil count in response to WRS for 3.5 hours. Some of the haematological values (PCV, RBC, $W B C, H b$, neutrophils and lymphocytes) showed significant increase $(P<0.001)$ in selenium and vitamin $E$ pre-treated groups. The result of the erythrocyte osmotic fragility showed that 3.5 hours of WRS increased haemolysis in the rats. The percentage haemolysis was significant/y highest in the active control group. Pre-treatment with selenium and vitamin E decreased the percentage haemolysis significantly. It was concluded that acute WRS exposure for 3.5 hours did not exert considerable effects on blood-forming organs, such that there was no inhibition of erythropoiesis and consequently, haemosynthesis. The MCV, MCH and MCHC remain normal because there was no significant destruction in RBC (size and shape) and decrease in haemoglobin content in the active controls and the decrease in neutrophil count was because neutrophils were involved in phagocytosis,during which some of the neutrophils have ruptured. The erythrocytes were susceptible to oxidative stress. Administration of selenium and vitamin $E$ singly or in combination ameliorated WRS-induced changes of the abovestudied parameters.
\end{abstract}

Keywords: Erythrocyte, Haemolysis, Neutrophil, Stress, Selenium, Vitamin E, Water immersion,

\section{INTRODUCTION}

Stress factor is an aversive stimulus which disturbs homeostasis (Anil et al., 2010). Stress induces organ injury causing diseases, including, gastric ulcers, hypertension, diabetes mellitus and cancer. A stress response is a natural reaction by the body against potentially harmful stimuli to enhance the chance for survival (Nayanataraet al., 2012). It induces the strain upon both emotional and physical endurance, which has been considered the basic factor in the aetiology of a number of diseases (Sheldon et al., 2012). During stress, there is increased generation of reactive oxygen species (ROS), associated with oxidative stress (Finkel and Holbrook, 2000). The ROS damage cell membranes via lipid peroxidation (Finkel and Holbrook, 2000). Lipid peroxidation generates a variety of relatively stable decomposition end-products, mainly a, $\beta$-unsaturated reactive aldehydes, such as malondialdehyde (MDA). Physiological studies have shown that stress from any source may influence the endocrine, haemopoietic and immune systems (Ebulunlomoet al., 2012). Cytokines and cortisol play an important role in the communication between these systems. Previous studies have shown that stress increases erythrocyte, neutrophil and platelet counts, whereas it decreases the number of lymphocytes, eosinophils and monocytes (Ebunlomoet al., 2012).

Stress induces distinct changes in haematological parameters (Artemyet al., 2013). It has been shown that erythropoietin production and erythrocyte differentiation are regulated by ROS, especially by $\mathrm{H}_{2} \mathrm{O}_{2}$. This means that ROS generation can suppress erythropoietin synthesis, whereas antioxidants can stimulate its synthesis (Anandet al., 2010). 
Blood parameters are probably the more rapid and detectable variations under stress and are fuel in assessing the health condition (Savithriet al., 2010). Erythrocytes are frequently used to evaluate oxidative stress. This is because their membrane is rich in polyunsaturated fatty acids, a primary target for reaction, involving ROS, and is very susceptible to lipid peroxidation (Alhassanet al., 2010). Selenium (Se) is an essential trace element and its low status in human has been linked to increased risk of various diseases (Ujang, 2008). Vitamin E (a-tocopherol) is a lipid-soluble antioxidant and a well-accepted first line defence mechanism against lipid peroxidation. It functions as a chain-breaking antioxidant for lipid peroxidation in cell membranes and as a scavenger of ROS such as superoxide anion, hydrogen peroxide and single oxygen (Ibrahim et al., 2010). The objective of the study was to determine the effect of selenium and vitamin $E$ on some haematological parameters and red blood cell osmotic fragility changes due to WRS in Wistar rats.

\section{MATERIALS AND METHODS \\ Experimental Animals}

Thirty five (35) Male Wistar rats weighing 200-220 g purchased from the Department of Pharmacology, Ahmadu Bello University, Zaria, were used in the study. They were fed standard laboratory diet and given access to drinking water ad libitum. This study was conducted in accordance with internationally accepted principles for laboratory animal use and care.

\section{Chemicals}

The antioxidants, sodium selenite pentahydrate $\left(\mathrm{Na}_{2} \mathrm{SeO}_{3} \cdot 5 \mathrm{H}_{2} \mathrm{O}\right)$, and a- tocopherol (vitamin $\left.\mathrm{E}\right)$ in the study were of analytical grade, and were purchased from Sigma (chemical Co. (St. Louis, MO, USA).

\section{Experimental Design}

The rats were anaesthetized with chloroform by inhalation and were kept conscious during the experiment. There after no additional anaesthetic was applied. The four limbs of each rat were bound on a wooden board $(25 \mathrm{~cm} \times 19 \mathrm{~cm})$ with upper limbs anchored at horizontal position, and the lower limbs extended downwards as reported by Shuet al. (2012). In WRS group, the animals were restrained after recovery from the anaesthesia, and the anchored plate were immersed to the level of xiphoid process vertically (head up) in water bath thermostatically-controlled at $23 \pm 0.5^{\circ} \mathrm{C}$ (Shu et al., 2012). The stress procedure lasted for 3.5 hours. The animals were subdivided into five groups of seven rats each as follows:-

Group I: Passive control animals (unstressed control)

Group II: Animals received distilled water as the vehicle at $5 \mathrm{ml} / \mathrm{kg}$ body weight orally for 3 days + WRS (active control).

Group III: WRS + vitamin E (250mg/Kg body weight) orally for 3 days (Vivian et al., 2011)

Group IV: WRS + selenium pentahydrate $(100 \mu \mathrm{g} / \mathrm{Kg}$ body weight) orally for 3 days (Jeong-Hwan et al., 2012).

Group V: WRS + vitamin E + selenium pentahydrate for 3 days.

At the end of this experimental procedure, animals were released from the plate and anaesthetized. Blood samples were collected through cardiac puncture (Ebunlomoet al., 2012).

\section{Determination of Haematological Parameters}

Red blood cell (RBC) count was carried out using the method of Akinnuga et al. (2011). Blood sample was diluted to 1:200 with Hayem's fluid, which was used to preserve and then count the corpuscles with a Neubauer counting chamber (New Improved Neubauer Counting Chamber. Sussex, England No 87323), under a light microscope. The counting of total white blood cells (WBCs) was done according to the method of Akinnugaet al. (2011), using a diluting fluid (Turk's fluid) in a ratio of $1: 20$. Haemoglobin $(\mathrm{Hb})$ concentration of the blood and pack cell volume (PCV) were estimated by the macrohaematocrit method. Erythrocytic indices ofmean corpuscular volume (MCV), mean corpuscular haemoglobin $(\mathrm{MCH})$, and mean corpuscular haemoglobin concentration $(\mathrm{MCHC})$ were calculated from values of RBC, PCV and $\mathrm{Hb}$ as follows (Salehet al., 2010).MCV (fl) $=$ PCV (\%) $\times 10 /$ RBC count. $\mathrm{MCH}(\mathrm{pg})=\mathrm{Hb}(\mathrm{g} / \mathrm{dL}) \times 10 / \mathrm{RBC}$ count. $\mathrm{MCHC}$ $(\mathrm{g} / \mathrm{dL})=\mathrm{Hb}(\mathrm{g} / \mathrm{dL}) \times 100 / \mathrm{PCV}(\%)$.

\section{Evaluation of Erythrocyte Osmotic Fragility}

The erythrocyte osmotic fragility test was determined using the method of Faulkner and King (1970) as described by Olayinka et al. (2011). Briefly, a set of 10 test tubes containing $0.1 \%$ to $0.9 \%$ concentration of sodium chloride $(\mathrm{NaCl})$. Each tube contained $5 \mathrm{~mL}$ of the corresponding sodium chloride and they were arranged serially in a rack of 10 tubes. A pipette $(1 \mathrm{~mL})$ was used to transfer $0.02 \mathrm{~mL}$ of blood into each of the 10 test tubes. The contents of the test tubes were gently mixed by inverting each test tube five times and allowing it to stand at room temperature $\left(26^{\circ} \mathrm{C}\right)$ for 30 minutes. Thereafter the content of the test tubes was centrifuged at $2000 \times \mathrm{g}$ for 10 minutes. The supernatant was then transferred in a glass cuvette and the absorbance of the supernatant was measured at a wavelength $540 \mathrm{~nm}$ using a spectrophotometer. The percentage haemolysis was calculated according to Faulkner and King (1970) as follows:

Percentage haemolysis (\%) =

$$
\text { Optical density of the test } \times 100
$$

Optical density of the standard (Distilled water.

\section{Statistical Analyses}

Results were computed for mean values + S.E.M. Statistical comparisons between variables were carried out using one way analysis of variance, and Tukey's post-hoc test was used to compare the differences between the means. Values of $\mathrm{P}<0.05$ were considered significant.

\section{RESULTS}

The values of the haematological parameters obtained in the various groups. PCV (47.14 $\pm 0.67 \%)$, RBC $\left(4.80 \pm 0.14 \times 10^{12} / \mathrm{L}\right), \mathrm{Hb}(15.90 \pm 15.90 \pm 0.29$ $\mathrm{g} / \mathrm{dl}), \mathrm{WBC}\left(7.18 \pm 0.44 \times 10^{12} / \mathrm{L}\right), \mathrm{MCV}(9.88 \pm 0.36$ $\mathrm{fL}), \mathrm{MCH}(33.01 \pm 1.19 \mathrm{pg})$, and $\mathrm{MCHC}(33.49 \pm 0.36 \mathrm{~g} /$ $\mathrm{dL})$, were not significantly $(P>0.05)$ different in active control as compared with the corresponding values in passive controls. 
The values of PCV, RBC in all groups pre-treated with selenium and vitamin $E$ were significantly $(P<$ 0.001)higher as compared with values of the active controls, The WBC counts in pre-treated groups were significantly $(P<0.001)$ higher in WRS plus Se group, when compared with the count recorded in active controls. The values of $\mathrm{MCV}, \mathrm{MCH}$ and $\mathrm{MCHC}$ did not show any significant $(P>0.05)$ difference betweenthe pre-treated groups and those of the active controls. The neutrophil, lymphocyte counts were significantly $(P<$ $0.05)$ higher when the active controls was compared with that of the passive controls. There was no significant difference between the mean monocyte counts recorded of active and passive controls. The mean counts of neutrophils, lymphocytes in all the pretreated groups were higher $(P<0.05)$, when compared with that of the active controls. There was no significant difference in the mean count of monocytes in the pretreated groups, when compared with that of the active control (Table 1).

\section{Erythrocyte Osmotic Fragility Test}

The percentages of haemolysis at different concentrations of $\mathrm{NaCl}$ were significantly $(P<0.001)$ higher in active controls compared with the corresponding percentages in passive controls. A significant decrease $(P<0.001)$ in percentage haemolysis was recorded in selenium and vitamin $\mathrm{E}$ pretreated groups, when compared with those of the active controls, and the decrease was higher in selenium and vitamin $\mathrm{E}$ pre-treated group (Figure1).

\section{DISCUSSION}

The changes in haematological parameters in Wistar rats, subjected to WRS and the effects of selenium and vitamin $E$ in attenuating some of the adverse effects were one of the focal points of the present study. The result of the present study showed that there were no significant changes in PCV, $\mathrm{Hb}, \mathrm{RBC}, \mathrm{WBC}, \mathrm{MCV}, \mathrm{MCH}$, $\mathrm{MCHC}$, Lymphocytes and monocytes in response to WRS for 3.5 hours in the active controls in comparison to passive controls (Table 1 ). The reason for this result might be that WRS for 3.5 hours did not exert considerable effects on blood-forming organs, such that there was no inhibition of erythropoiesis and consequently, haemosynthesis. The $\mathrm{MCV}, \mathrm{MCH}$ and $\mathrm{MCHC}$ remain normal because there was no significant destruction in RBC (size and shape) and decrease in haemoglobin content in the active controls. A significant decrease in neutrophil count was observed when the active controls were compared with the passive controls. This finding may be because neutrophils are involved in phagocytosis, during which some of the neutrophils have ruptured. The present study was in agreement with findings of Ebunlomoet al. (2012), who also found no significant increase in the values of PCV, $\mathrm{RBC}, \mathrm{Hb}$, and MCV. Although the present study contrasts the significant increase in $\mathrm{Hb}$ and MCV values reported by Maeset al. (1998), number of some of the haematological values (PCV, RBC, WBC, $\mathrm{Hb}$, neutrophils and lymphocytes) showed significant increases in selenium and vitamin E pre-treated groups. The findings suggests that selenium and vitamin E as antioxidants increased the immune function of the rats.
The results of the erythrocyte osmotic fragility showed that 3.5 hours of WRS increased haemolysis in the rats. The percentage haemolysis was significantly highest in the active control group, when compared with passive controls. The increased erythrocyte osmotic fragility may be attributed to effects of stress, to cause increased in ROS generation in animals (Olayinkaet al., 2011). The erythrocytes are highly susceptible to oxidative stress apparently because of high amount of poly-unsaturated fatty contents in their membrane (Nazifiet al., 2009). The present study showed that pretreatment with selenium and vitamin $\mathrm{E}$ decreased the percentage haemolysis in the pre-treated groups, compared to the active controls. This result agreed with the findings of Alhassanet al. (2010), who suggested that the beneficial effects of administration of antioxidant vitamins in ameliorating the adverse effects of stress including the susceptibility to haemolysis in heat-stressed rats.

\section{CONCLUSION}

Acute WRS for 3.5 hours carried out in this study was found to cause significant alterations in some haematological and erythrocyte osmotic fragility. Pretreatment with selenium or vitamin $\mathrm{E}$ singly and/or in combination ameliorated some of the recorded adverse effects of water immersion restraint stress. 
Bajopas Volume 8 Number 2 December, 2015

\begin{tabular}{|c|c|c|c|c|c|}
\hline Parameter & Passive Control & Active Control & WRS +Se & WRS+VE & WRS+Se+VE \\
\hline PCV (\%) & $47.14 \pm 0.67$ & $48.14 \pm 0.51$ & $55.29 \pm 0.89 * *$ & $56.86 \pm 0.96 * *$ & $55.29 \pm 1.36^{* *}$ \\
\hline $\mathrm{Hb}(\mathrm{g} / \mathrm{dL})$ & $15.90 \pm 0.29$ & $16.04 \pm 0.17$ & $18.29 \pm 0.29 * *$ & $18.90 \pm 0.32 * *$ & $18.86 \pm 0.44 * *$ \\
\hline $\operatorname{RBC}\left(\times 10^{12} / \mathrm{L}\right)$ & $4.80 \pm 0.14$ & $4.59 \pm 0.09$ & $5.06 \pm 0.10 * *$ & $5.28 \pm 0.09 * *$ & $5.37 \pm 0.11 * *$ \\
\hline WBC $\left(\times 10^{9} / \mathrm{L}\right)$ & $7.18 \pm 0.44$ & $7.94 \pm 0.54$ & $6.09 \pm 0.36^{* *}$ & $6.46 \pm 0.33$ & $6.43 \pm 0.33^{*}$ \\
\hline MCV (fL) & $9.88 \pm 0.36$ & $10.46 \pm 0.25$ & $10.35 \pm 0.44$ & $10.51 \pm 0.43$ & $10.35 \pm 0.32$ \\
\hline $\mathrm{MCH}(\mathrm{pg})$ & $33.01 \pm 1.19$ & $34.94 \pm 0.79$ & $33.40 \pm 1.26$ & $36.56 \pm 0.68$ & $34.16 \pm 1.08$ \\
\hline $\mathrm{MCHC}(\mathrm{g} / \mathrm{dL})$ & $33.49 \pm 0.36$ & $33.34 \pm 0.43$ & $32.98 \pm 0.44$ & $34.98 \pm 0.43$ & $32.58 \pm 0.32$ \\
\hline Neutrophils (x 1000/L) & $245.59 \pm 15.46$ & $222.29 \pm 27.31^{*}$ & $243.79 \pm 3.86 *$ & $244.03 \pm 2.59 *$ & $245.30 \pm 3.84 *$ \\
\hline Lymphocytes (x 1000/L) & $443.94 \pm 27.63$ & $487.36 \pm 38.66$ & $520.53 \pm 32.31 *$ & $553.41 \pm 32.03 *$ & $555.85 \pm 34.18^{*}$ \\
\hline
\end{tabular}

$* *=\mathrm{P}<0.001$ Significant Differences between active and passive controls and also active control compared with selenium and vitamin $\mathrm{E}$ groups. 


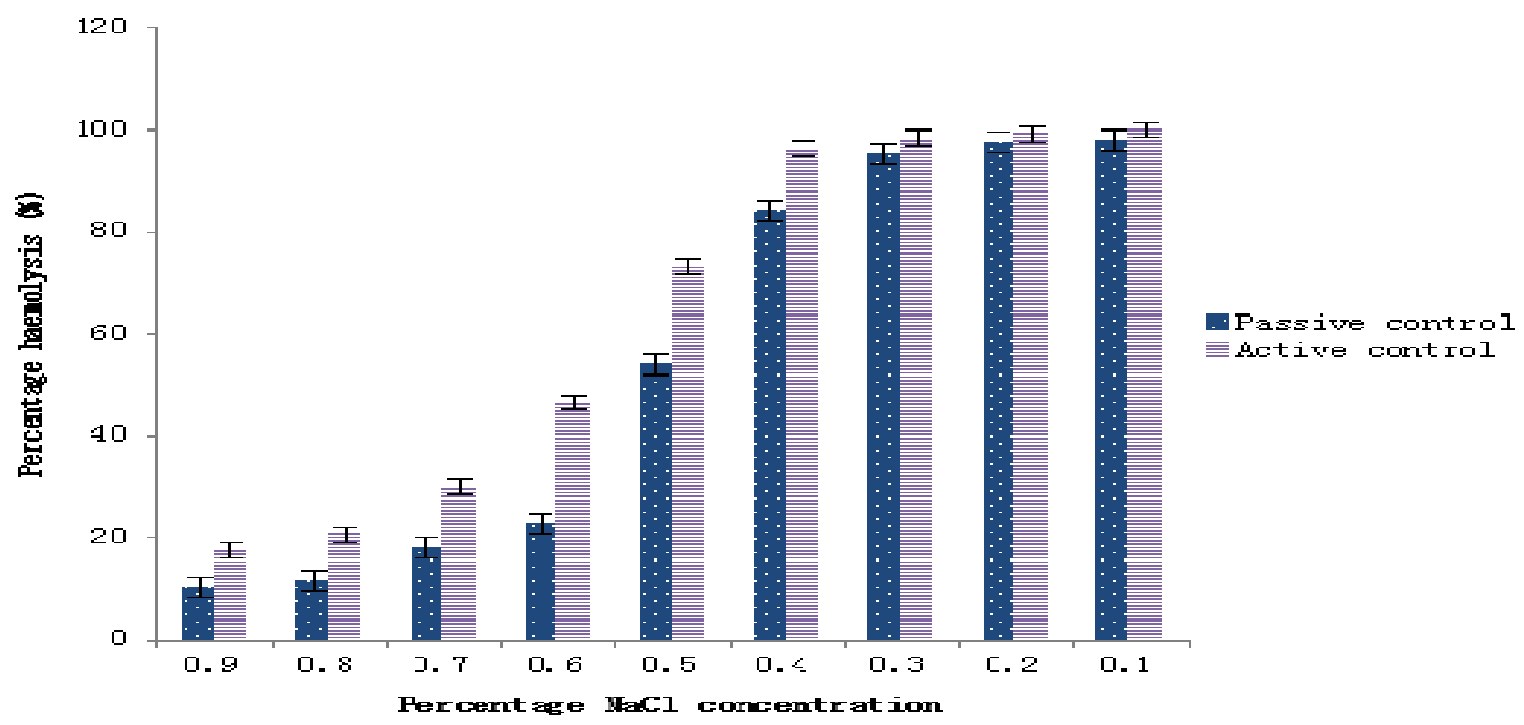

Figure 1:Effects of water-immersion restraint stress on erythrocyte osmoticFragility in Wistar rats $a, b=$ means with different superscript letters are significantly $(P<0.001)$ different $(n=7)$.

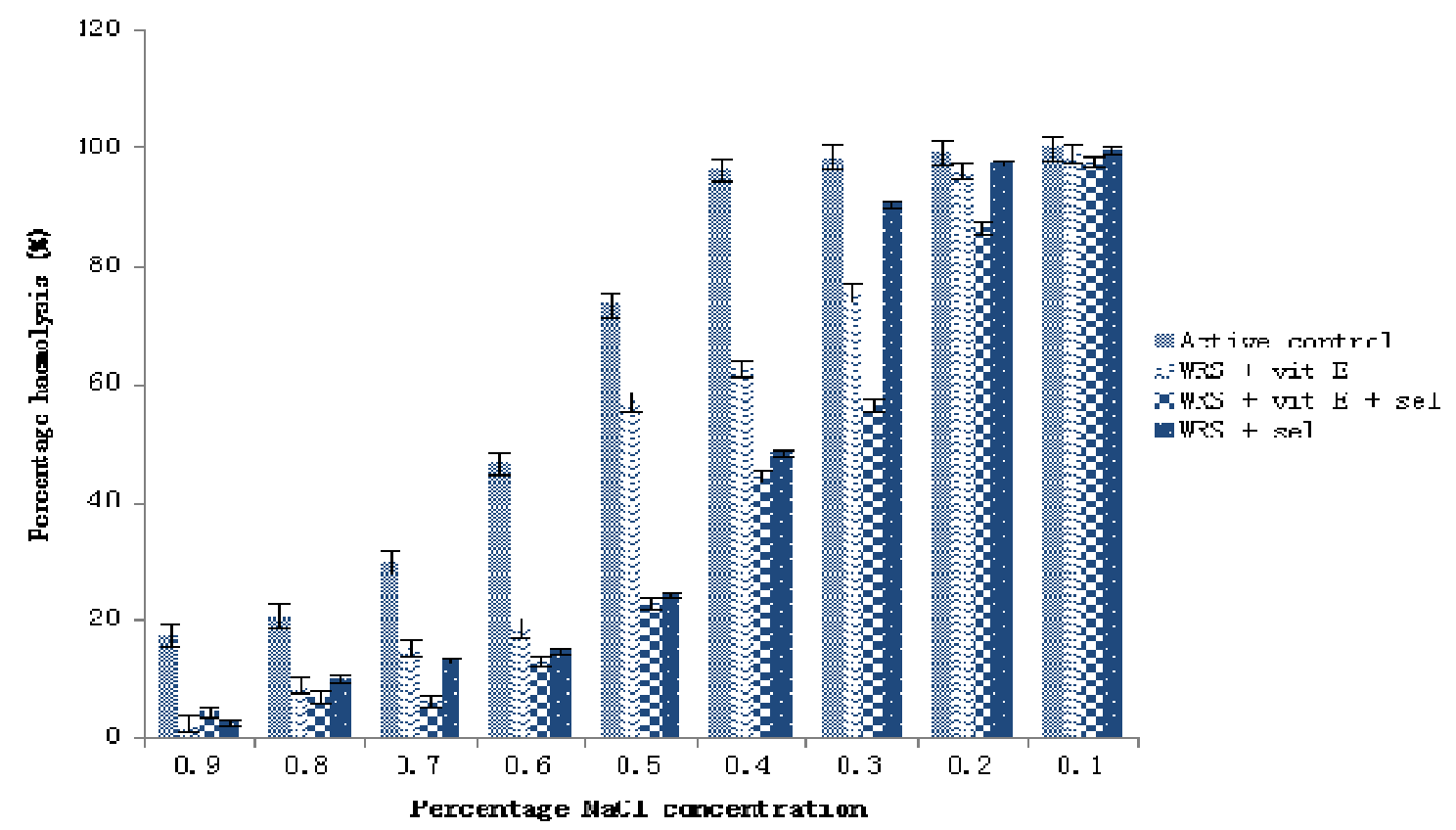

Figure 2: Effects of selenium and vitamin E on erythrocyte osmotic fragility in rats subjected to water immersion restraint stress

$a, b, c, d=$ values with no common super script letters are significantly $(P<0.001)$ different

Pass. Cont. $=$ Passive control (Non stress animals). Act. Cont. = Active control (WRS + Distilled water).WRS + vit $\mathrm{E}$ $=(\mathrm{WRS}+$ vitamin $\mathrm{E}) . \mathrm{WRS}+$ vit $\mathrm{E}+$ sel $=(\mathrm{WRS}+$ vitamin $\mathrm{E}+$ selenium $) \cdot \mathrm{WRS}+$ sel $=(\mathrm{WRS}+$ selenium $) . \mathrm{WRS}=$ water immersion restraint stress. 


\section{REFERENCES}

Akinnuga, A.M. Bamidele, O. Ekechi, P. and Adeniyi, O.S. (2011). Effects of an ethanolic leaf extract of Gongronemalatifolium on haematological parameters in rats. African Journal of Biomedical Research. $14: 153$ - 156.

Alhassan, A. Mohammed, A.M. Joseph, O.A. Ambali, F.S. Shittu, M. Adenkola, A.Y. and Salawu, E.O. (2010).Effects of co-administration of antioxidants on erythrocytes osmotic fragility of Wistar rats during hot-dry season. European Journal of Scientific Research, 46 (1): 73-79.

Anand, P. Rajakumar, D. John, W.F. and Balasubramanian, T. (2010). Effects of oral administration of antioxidant Taurine on haematological parameters in wistar rats. Pakistan Journal of Biological Sciences, 13 (16) : 785-793.

Anil, K., Ruchika, G., Vaibhav, G. and Puneet, K. (2010). Possible role NO modulators in protective effect of trazodone and citalopram (antidepressant) in acute immobilization stress in mice. Indian Journal of Experimental Biology, 48: $11-31$.

Artemy, V.N. Tatyana, V. T. Michael, I.K. Lev, N.K. Vadim, A.I. and Vladimir, I.M. (2013).Effect of acute immobilization on the hematological, red-ox and rheological parameters of erythrocytes in rats.Al Ameen Journal of Medical Sciences, 6 (1): 88-92.

Dhabhar, F.S. Miller, A.H. McEwen, B.S. and Spencer, R.L. (1995).Effects of stress on

Nayanatara, A..K., Tripathi, Y. Nagaraj, H.S., Jeganth P.S., Ramaswamy,C. and Ganaraja,B. (2012). Effects of chronic immobilization stress on some selected physiological, biochemical and lipid parameters in Wistar Albino Rats. Research Journal of Pharmaceutical, Biological and Chemical Sciences, 3(1): 34-42.

Nazifi, S. Saeb, M. Bashshani, H. and Saeb, S. (2009). Influence of road transportation during hotsummer conditions onoxidative status biomarkers in Iranian dromedary camels (Camelusdromedarius). African Journal of Biochemistry Research, 3: 282-287.

Olayinka, O.A. Joseph O.A. Peter, I.R. Ndazo, S.M. David, O.O. and Adeshina, Y.A. (2011). Effect of ascorbic acid administration on erythrocyte osmotic fragility of pigs transported by road during the hot-dry season. Veterinary Research Communication, 35: 245-254.

Saleh, Z. Giti, H. Asghar, G. Shahrok, P. and Nilufar, S. (2010). Haematological parameters and osmotic of red blood cell in experimentally induced hyperthyroidism in rats. International Journal of Endocrinology and Metabolism, 8 (2) : 74 -78.

Savithri, P. Ravi, S and Jacob, P.D. (2010).Changes in haematological profiles of albino rats under chlorpyrifus toxicity. International Journal of Pharmaceutical and Bio Science, 1(3): 1-7.

Sheldon, C. Denise, J.D. William, J.D. Gregory, E.M. Ellen, F. Bruce, S.R. and Ronald, B.T. immune cell distribution.Dynamics and hormonal mechanism.Journal of Immunology, 154 (10): 5511-5527.

Ebunlomo, A.O., Odetola,A.O., Bamidele,O.,Egwurugwu, J.N., Maduka,S.,andAnupe, J. (2012). Effects of Emilia praetermissa leaf extract on the heamatological biochemical parameters of stress induced ulcerated wister rats. African Journal of Biochemistry Research, 6(14): 185189.

Finkel, T. and Holbrook, N.J. (2000).Oxidants, oxidative stress and the biology of ageing. Nature, 408: 239-247.

Faulkner, W.R. and King, J.W. (1970). Manual of Clinical Laboratory Procedures.

Chemical Rubber Company, Cleveland, Ohio, USA 354 Pp.

Ibrahim, A.I. Yusof, K. Mohd, I.N. Mohd, F. and Nur, A. (2010). The effects of palm vitamin $E$ on stress hormonal levels and gastric lesion in stress - induced rats. Achieved of Medical Sciences, 8(1): 22-29.

Jeong-Hwan, K. Shin-Hyung, P. Soo-wan, N. and YungHyun, C. (2012).Gastro protective effect of selenium on ethanol-induced gastric damage in rats.International Journal of Molecular Sciences, 13(5): 5740-5750.

Maes, M. Vander, P.M. and Vangastel, A. (1998). Influence of academic stress on haematological measurements in subjectively healthy volunteers. Psychiatry Research, 80: 201-212

(2012). Chronic stress, glucocorticoid receptor resistance, inflammation and diseases risk. Proceedings of the National Academy of Sciences, 109(16): 5995-5999.

Shu, G. Qian, G. Qing, J. Wei, H. Xue, G, andJi-Min, C. (2012). Gastric mucosal damage in water-immersion stress: Mechanism and prevention with GHRP-6. World Journal of Gastroenterology, 18 (24): 3145-3155.

Ujang, T. (2008). Selenium: Its role as antioxidant in human health. Environmental Health and Preventive Medicine, 13(2): 102-108.

Vivian, M.C. Yazmin, R.C. Yohani, P.G. Ambar, O.Y. Sonia, J.D. Rosa, M.F. and Daisy, C.Q. (2011). Effects of grape seed extract, vitamin $\mathrm{C}$ and vitamin $\mathrm{E}$ on ethanol and aspirin-induced ulcers. Advance in Pharmacological Sciences http://dx.doi.org/10.1155/2011/740687 